This item was submitted to Loughborough's Research Repository by the author.

Items in Figshare are protected by copyright, with all rights reserved, unless otherwise indicated.

\title{
Management issues regarding e-commerce and the internet: 20 critical questions managers should ask before plunging into e-commerce!
}

\section{PLEASE CITE THE PUBLISHED VERSION}

\section{PUBLISHER}

(c) IEEE

\section{VERSION}

VoR (Version of Record)

\section{LICENCE}

CC BY-NC-ND 4.0

\section{REPOSITORY RECORD}

Shah, Nilpa, and Ray Dawson. 2019. "Management Issues Regarding E-commerce and the Internet: 20 Critical Questions Managers Should Ask Before Plunging into E-commerce!”. figshare.

https://hdl.handle.net/2134/4112. 
This item was submitted to Loughborough's Institutional Repository (https://dspace.lboro.ac.uk/) by the author and is made available under the following Creative Commons Licence conditions.

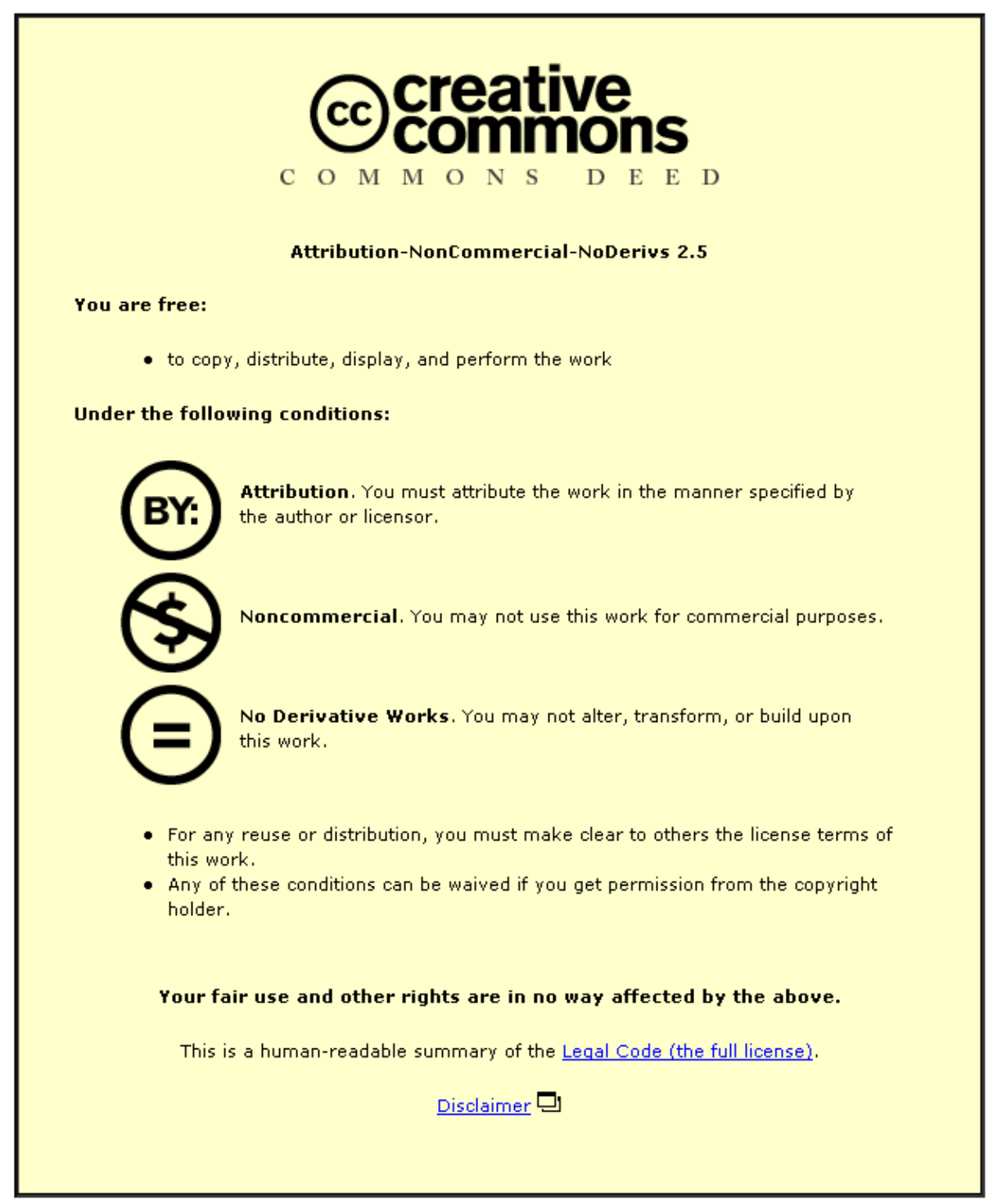

For the full text of this licence, please go to: http://creativecommons.org/licenses/by-nc-nd/2.5/ 


\title{
MANAGEMENT ISSUES REGARDING E-COMMERCE AND THE INTERNET
}

\author{
20 critical questions managers should ask before plunging into e-commerce!
}

\author{
Nilpa Shah and Ray Dawson \\ Loughborough University, Loughborough, UK \\ Email: N.N.Shah@lboro.ac.uk, R.J.Dawson@lboro.ac.uk
}

\begin{abstract}
The drivers for electronic commerce are both technological (under the tremendous pressure of innovation) and business oriented. The authors have found technological issues drive most industrialists, with the business drivers being vague. However both technology and business drivers should play an important part. As Cathy Benko (Deloitte consulting) had said, "for more than two centuries the industrial business model has used a single linear approach to change, predict what customers will want, design resources and organize people to serve those wants, then implement according to management's plan and design. Today this model of Predict-design-implement is no longer viable- in fact, it is dead." [1]

This paper will identify managerial issues regarding ecommerce and the Internet. Chan and Swatmann [2] noted that management involvement is imperative for the success of electronic commerce implementation. The size and popularity of the Internet have grown enormously during the past few years and continue to grow at phenomenal rates. The risk of entering ecommerce is many and it is important that the issues are understood. This paper has identified the issues, which need to be considered and 20 key questions, which need to be addressed before entering into ecommerce.
\end{abstract}

Keywords. Management, Change, Strategy, Skills, Risk.

\section{INTRODUCTION}

The Internet has paved the way for many new companies and exciting business models. It has also opened doors for inexperienced people, driven by great ideas, well financed and backed by enthusiastic management teams, but lacking the professional management skills to enable them to create lasting businesses. The authors believe that once you remove the 'Dot-Com' and the hype of the Internet, you are left with just another business with normal business issues.
A business that has people, technology, suppliers and partners, is a business that includes all aspects of management, such as planning, budgeting organizing and controlling - all the attributes necessary to create a solid business foundation. The authors believe managing IT is essentially the same as managing any other discipline. Managers do not require an in-depth knowledge of computers or telecommunications to manage IT effectively. What they need to understand is how IT can contribute effectively to achieving key business objectives such as improving quality, reducing time to market, and improving productivity within the organization.

E-commerce is a hugely encompassing area for management, but there is rarely a consensus on the meaning of the term. A working definition of this paper is "buying things on the Internet" [3]. Whether trading between business and consumer or business-tobusiness, a transaction normally involves a transfer of value between two or more parties in exchange for physical goods or services.

\section{MANAGER'S ROLE}

Companies, which have been successful rate management involvement as the highest, factor in the implementation of e-commerce[4]. This paper examines the role managers should play in a move to ecommerce. Senior managers have the authority to embrace change and recognize the strategic importance of e-business to the company's future. Managers are required to think strategically, creatively and "outside the box" about the opportunities and challenges of ebusiness. They also need to be prepared to reengineer processes to improve existing processes. Managers have the power and authority to implement industry wide standards and should have a realistic view of significant effort and funding to make the investment.

\subsection{People's general perception of e-commerce}

Two most common views against e-commerce are:-

- Think about it but won't do it

- E-commerce will hopefully go away 
The business risk is high as seen from Amazon.com, Boo.com and Ebay. However the rewards can be high, though a description of the many advantages of ecommerce is beyond the scope of this paper.

\subsection{Statistics}

Neamond Bond associates have found that [5]:-

- $91 \%$ of dot.coms view branding as a top management issue.

- $71 \%$ of bricks and mortar companies view profitability as a top management issue.

Figure 1 below shows the growth of E-commerce worldwide and its predicted trend in 2002

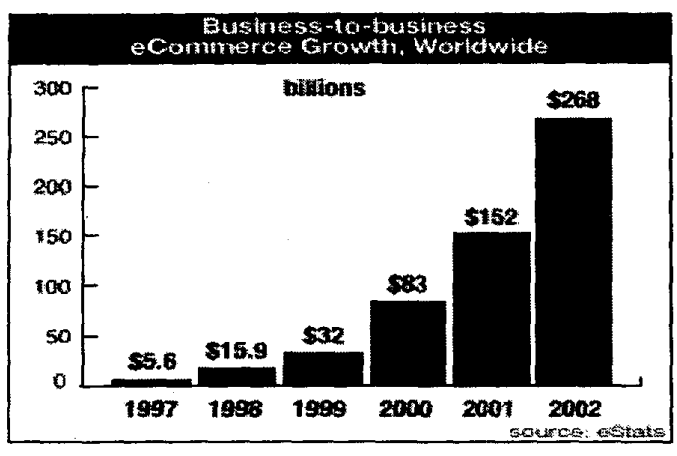

Figure 1.

Business to Business e-commerce growth world-wide

Neamond advice's managers dealing with IT should filter out the buzz words, ensure that the key system initiatives tie in with the business objectives, and ensure there is strong partnership with the IT department to achieve this [5].

\section{MANAGERIAL ISSUES OF E-COMMERCE}

Cragg and King discovered that the strongest inhibiting factors for small firms were lack of information systems knowledge, lack of managerial time, poor support, and limited financial resources [6]. If management is not made aware of new and enabling technology, then it is not surprising that they are unwilling to adopt electronic commerce.

The fast growing and changing field of e-commerce means the following issues must be considered:

\section{(1) Managing resistance to change and increasing} awareness

E-Commerce can result in a fundamental and radical change in the manner in which business is done. Therefore, resistance to change from employees, vendors and customers may develop. Education, training and publicity over an extended time period are possible solutions to the problem. Research has shown that organising training and awareness programs to make staff conversant with what happens has had significant effect in improving understanding of systems and technologies, which in turn has lead to greater acceptance of the implementation [7]. It is also important to demonstrate the advantages and benefits gained, addressing the motivating factors.

\section{(2) Integration of electronic commerce into the} business environment

Electronic commerce needs to be integrated with the rest of the business. Some integration issues involve planning, competition for corporate resources with other corporate projects and interfacing e-commerce with databases, existing IT applications and infrastructure. It should take account of all functions within the organisation such as enterprise resource planning, customer relationship management, supply chain as well as people and processes. That means management needs to deliver integrated skill sets alongside the understanding of the end-to-end business design and the implications that an e-business initiative has throughout the entire organisation.

(3) Lack of qualified personnel and outsourcing A possible difficulty in implementing e-commerce relates to human nature. The technology is new to many IS directors and employees and so may require new sets of skills. Very few people have expertise in ecommerce. There are many implementation issues that require expertise, such as when to offer special promotions on the Internet, and what kind of customer incentives is appropriate. For this reason, it may be worthwhile to outsource some electronic commerce activities. Companies who recruit should follow the Belbin analysis of team working and personal characteristics of each individual suited for the job to get the right set of people working together [8].

(4) Conducting a cost benefit analysis

Many intangible benefits and lack of experience may make costs and benefit estimates grossly inaccurate yet it still must be done. The problem is that e-commerce is too new for any company to have any substantial track record of e-commerce implementation. Furthermore, those companies that have established themselves in e-commerce do not necessarily provide the best example, with few showing any profit or any prospect of profit in the foreseeable future.

\section{(5) Alliances}

Joining an alliance or consortium of companies to explore electronic commerce and its implementation before making crucial decisions may be a means of reducing risk. However, as was seen in the case of AOL and Netscape, it can bring diverse companies together and therefore increases uncertainty. The 
problem is which alliance to join, or what kind of alliance to form and with whom.

\section{(6) Implementation plan}

Because of the complexity and multifaceted nature of e-commerce, the importance of preparing the implementation plan becomes strategically more significant. Such a plan should include goals, budgets, timetables, and contingency plans and should address mainly the legal, financial, technological, organizational and ethical issues that can surface through implementation. Management plays a significant and valuable role in influencing implementation success. They have to be there to provide support, both technical and emotional, to staff in the implementation.

\section{(7) Responding to e-mail}

Some companies are flooded by email queries, requests or complaints. It has to be considered whether the company has the right infrastructure, both in terms of the computer equipment and the trained staff to handle the volume of electronic communication.

(8) Strategy towards electronic commerce Generally speaking there are three major options:

- To lead: conduct large scale innovative ecommerce activities

- To watch: do nothing, but carefully watch what is going on in the field to recognise the moment when e-commerce is mature enough , within the sector, to enter it.

- To experiment: start some e-commerce experimental projects.

The issue is to decide which of these options will give the greatest business benefit, or even if some combination is possible.

\section{(9) Privacy}

Most electronic payment systems know who the buyers are, therefore it may be necessary to protect their identity. Other privacy issues may involve tracking of Internet user activities by in-house monitoring of web house activities and to follow the Data Protection Act.

\section{(10) The human element}

Another human factor relates to the operation of sales. Sales people who work on commission are accustomed to being in control of the flow of certain information, and the implementation of an e-commerce can lead to personnel dissatisfaction as customers bypass the sales person and revenues become more widely distributed within the company. E-commerce can also produce issues of lack of flexibility and transparency. For example a company that previously set all prices by negotiation with customers will be restricted in its flexibility if prices are made available to all on the
Internet. This can cause jobs to be redefined within the sales team and elsewhere in the company.

\section{(11) The impacts}

The impacts of e-commerce on organisational structure, people, marketing procedures, and profitability may be dramatic. Therefore establishing a committee or organisational unit to develop strategy and to manage electronic commerce is necessary. The success or failure of electronic commerce within an organisation can be summarised as a response to both internal factors driven by critical issues such as managerial responses and organisational culture and by external factors (as described by Thong and Yap[9]) such as the need for competitiveness and adding business value as shown in Figure 2.

Internal
issues
Internal issues
+ve (Push)
- Driven by the e-commerce group and manager,
- E-commerce is seen as a mechanism to deliver
efficiencies and cost reduction.
-ve (Pull)
-Uncertainty about what e-commerce is
-Strongly vested interest in other technologies
-Overworked staff
External issues
+ve (Push)
-Reduced budget allocation
-Increasing client expectations.
-ve (Pull)
-Negative perceptions of clients who see nothing in
it for them

Figure 2: Issues in Electronic commerce applications

Intranets and GroupWare force people to cooperate and share information. Therefore their use can lead to significant changes in both organisational culture and the execution of business process reengineering. Further impacts may be felt in corporate structure and the redistribution of organisational power. Companies must be prepared for the internal politics caused by such an organisational change. 


\section{(12) Ethical issues}

By introducing e-commerce, managers may be faced with ethical issues such as, what to do with the old employees who are difficult to retrain? Implementing organisation transformation by the use of IT may encourage companies to involve unethical or even illegal actions.

Companies may also use IT to monitor activities of their employees and customers, leading to an invasion of the privacy of individuals. "Surfing the Internet" is exciting yet time consuming activity. Employees can be tempted to surf during work hours. Control can be achieved by limiting the information that employees have access to and by using special monitoring software, but this may have an adverse affect on morale and lead to employees feeling their company is taking a "big brother" attitude.

\section{(13) Security of com munication}

Communication via networks raises the issues of integrity, confidentiality, and security of the data being transferred. These are technical issues that lead to management issues of how well the company and its customers are prepared to trust the communication and how this will then affect their behaviour.

\section{(14) Name Image and Cyber Squatting}

The many companies going into dot-com start-up has resulted in brand name confusion, which has become a race to get their first and protect one's company's own image. This problem is increased by some Internet opportunists purposely registering names of web sites that conflict with established company names. This practice, known as cybersquatting, is done in the hope that those companies will pay large sums to buy back the web site name. Any previous registration of the company or product names as a "dot_com" by another party could seriously affect the development of the company's owns name image.

\section{(15) Legal Issues}

The rise of the Internet has lead to many legal issues without any clear precedent or guide as to the correct legal position. What happens, for example, if a price is incorrectly advertised on the web? What is the contractual position of anyone who orders goods based on that price? What warnings and disclaimers need to be incorporated into the web site to protect the company from mistakes of this type? These are just some of the legal issues that need careful consideration when entering e-commerce.

\section{(16) Congestion}

Some people believe the increased use of the Internet will eventually lead to overload; therefore companies should develop a contingency plan to be less dependent on the use of the Internet. However this can affect company growth potential. The issue is how far a company can commit itself to rely on electronic trading.

These 16 management issues can each be divided into one or more main categories of risk, people, legal, technical and organisational issues as shown in Table 1 .

Table 1: Catagorisation of Management Issues

\begin{tabular}{|c|c|c|c|c|c|}
\hline Factors that causes issues & Risk issues & $\begin{array}{l}\text { People } \\
\text { issues }\end{array}$ & $\begin{array}{l}\text { Legal } \\
\text { issues }\end{array}$ & $\begin{array}{l}\text { Technical } \\
\text { issues }\end{array}$ & $\begin{array}{l}\text { Organizati } \\
\text { onal issues }\end{array}$ \\
\hline 1. Managing change & $v$ & $\checkmark$ & & & $\checkmark$ \\
\hline 2. Integration & $x$ & & & $\gamma$ & $\checkmark$ \\
\hline 3. Personnel & & $y$ & & & $\checkmark$ \\
\hline 4. Cost benefit & $\checkmark$ & & & & \\
\hline 5. Alliances & 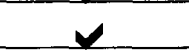 & & & & 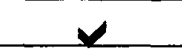 \\
\hline 6. Implementation & $v$ & $\checkmark$ & & & \\
\hline 7. Responding to e-mail & & $\checkmark$ & & $x$ & \\
\hline 8. Strategy & $V$ & & & & \\
\hline 9. Privacy & & & 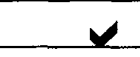 & 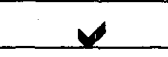 & \\
\hline 10.Human element & & $v$ & & & $v$ \\
\hline 11.Organizational impact & $y$ & $\checkmark$ & $v$ & $x$ & 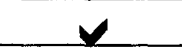 \\
\hline 12.Ethical issues & $v$ & & 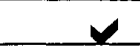 & $\checkmark$ & \\
\hline 13.Security & 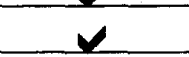 & & & $v$ & \\
\hline 14.Cybersquatting & & & $v$ & & \\
\hline 15.Legal issues & $v$ & & $v$ & & $x$ \\
\hline 16.Congestion & & & & $v$ & \\
\hline
\end{tabular}




\section{WHAT CAN MANAGERS DO?}

Having developed a list of key issues, the paper now turns to how managers should respond:-

(1) Build Inter-enterprise Shared Vision through Education. A picture of the future is required if a company is to know where it is going and what it is trying to build. Corporations cannot possibly arrive at their destinations if they do not have a clear vision of where that is. Few concepts are more mysterious than corporate vision: shared visions are not pearls of wisdom handed down from an enlightened CEO. Instead, shared vision comes from individual vision from customers, suppliers and individual employees. Shared vision brings about common directions, focus, and the motivation for personal, team and organisational learning. With genuine shared vision, not imposed corporate vision all workers across the organisations can accept change.

(2) Conduct Inter-enterprise Architectural Assessments and Gap Analysis. Peter Senge is Director of the Systems Thinking and Organisational Learning Program at MIT's Sloan School of Management. Senge calls systems thinking the "5th discipline" and the cornerstone of the learning organisation. [10] To be successful, e-Commerce teams must be masters of general systems thinking. Systems thinking provides a new perspective to business process analysis and redesign. Unfortunately, we only see bits and pieces of our company and industry in our day-today work. Systems' thinking is a formal discipline of management science that deals with whole systems and with the interconnections and interactions of the individual parts. Systems' thinking is also a learning method. Business team members can make assumptions about improved business processes and test those assumptions with the systems model. Feedback closes the loop and causes learning.

Applying the first principles of systems thinking, eCommerce teams can analyse the entire business ecosystem and discover opportunities for breakthrough value propositions made possible by the e-Commerce business platform. The analysis will focus on the new business capabilities afforded by the Net.

\section{KEY QUESTIONS FOR MANAGERS}

Before taking the critical step of entering e-commerce managers must be able to answer the following key questions:-

Q1) What is it that we can now do that we couldn't do before the availability of the Net? How does it affect the nature of existing products and services? Will e- commerce replace existing processes or will it be an additional process?

Q2) Who is our current and future e-Commerce customer? Will the previous customer base adapt to ecommerce or will e-commerce attract new customers?

Q3) How can we add compelling value to our present and future customers and still make a profit and maintain core competency? Will existing customers be attracted to the electronic medium by the easy access and extra information available or will they regret the loss of the personal touch? What do our e-commerce customer's want, convenience, lower prices, new products or services? Can the proposed company ecommerce process meet the expectations of the customer?

Q4) Should we cannibalise our own business? How is e-commerce going to be introduced? If it becomes a new, additional process can existing staff handle it or will new staff be needed? If so, how can the customer and product expertise be transferred to the e-commerce process? If, on the other hand, existing staff are used, can the run down or abandoning of existing processes be justified?

Q5) What can and should we outsource? Can we outsource much of the risk of introducing e-commerce by bringing in specialist companies who have experience in the technology and business expertise required? However, if the e-commerce is likely to be the companies main business in the future the loss of control could be a serious disadvantage.

Q6) How will the introduction of e-commerce affect the company's organisation and structure? Will new tiers appear in the company hierarchy or will it have the effect of flattening the organisational structure? The introduction of e-commerce can lead to the entire business's processes being re-engineered.

Q7) Can the introduction of e-commerce have a positive effect on the existing distribution network or supply source? Does the electronic medium allow us to increase the product range by becoming a supply-chain portal using the existing suppliers and distribution network?

Q8) What legal issues do we face? The company must understand the legal issues of contracts, taxation, confidentiality and intellectual property? It is likely that the company will need to seek expert advice on these issues.

Q9) What e-Commerce competitive threats do we face? Competition may not come from traditional competitors! For example in case of Internet banking, there was egg.com, which emerged from nowhere. How do we compare with our competitors in the 
introduction of e-commerce, are we leaders, fast followers or laggards? [11]

Q10) Are our trading partners ready to participate in eCommerce, or how soon will they be? To gain the full advantage of e-commerce it is necessary to make as many steps as possible electronic. It is possible that the success of the company's efforts in e-commerce may depend on its suppliers and customers' own ecommerce infrastructure.

Q11) How does e-Commerce change our pricing policies? Does e-commerce mean a loss of price flexibility, the transparency of the pricing reducing the ability to negotiate and offer discounts. The pricing of products compared with that of competitors becomes more critical when competitors are just a mouse click away.

Q12) How can we use the Internet to streamline business processes, reduce cycle time and become cost competitive? Can the electronic medium be used throughout all processes from purchase of supplies to distribution to the customer reducing costs and time to delivery?

Q13) What customer touch points do we need to reach now and in the future? That is electronic touch vs. people touch? In particular when do we need a personal touch and when is an electronic touch satisfactory?

Q14) What are the people skills required? New skills can range from the technical skills to handle the software and hardware to the business skills of emarketing and organisation. Does the company possess these skills and, if not, is retraining possible or will new appointments be necessary?

Q15) What technology is needed for the new architecture? Is the technology infrastructure aligned with current business objectives of cost and company growth and is it scalable, reliable, up to date and secure?

Q16) How important is the speed to enter the market? How do we measure, on a scale from world class to seriously inadequate? Is there a danger that we may come to the market too soon, before it is ready, or could we be too late and loose market share to our competitors?

Q17) What level of investment is required? What costs include implementing the hardware and software technology, outsourcing, training and recruitment. It must also be remembered that the rapid changes in ecommerce technology this investment will be ongoing, as new developments are appearing every day (for example even before computer e-commerce had established itself mobile phones introduced completely new technology and business issues to be considered).

Q18) Do we have well defined and up to date objectives? Do we have a vision of where we will be in one year? E-commerce has brought such rapid changes that many companies are being forced to revise strategies. Predicting the expansion of e-commerce is extremely difficult with even the "experts" being taken by surprise.

Q19) What are the critical success factors? These must be based on sound business principles. For example, Amazon.com has clearly been a marketing and technological success but its business success is yet to be proven. The stock market has certainly not been a reliable indicator of success with companies like Ebay.com and Boo.com moving from high valuation to bankruptcy almost overnight.

Q20) What are the e-business trends and the future and how will this impact the business? This means keeping. a careful watch on all new technological developments. changes in market and the effect of developments by new and traditional competitors.

These questions guide the assessment of the gap analysis of "could be" architecture to be envisioned and documented. Then current elements can be documented, providing a description of the "as is" architecture. Gap analysis then ensues, revealing the people, processes and technology needed to implement elements of the new architecture. The result of assessment and gap analysis forms the basis for developing an initial strategy plan for e-Commerce.

\section{CONCLUSION}

In order to have a successful e-commerce development it is necessary to have board level commitment, and support from all departments, people involved and stakeholders. Projects have been known to fail without such commitment. Thus, if the twenty questions are answered and understood by all parties this would help and would also minimise the risks faced by the issues.

E-Commerce is not an end state. It is a new business platform that will grow and evolve. The secret to sustainable E-Commerce success is to think and plan in terms of overall architecture, but act in incremental steps. To manage risk, a company's very first eCommerce initiative might well be a simple "paper replacement" project to demonstrate the proof-ofconcept in a well-controlled, internal environment. Processes are untouched, just the user interface is modified. Then the scope of the project can be expanded to include easily managed process changes. Therefore the 20 questions should be continually reviewed.

Although e-commerce is a relatively recent phenomenon, those companies that are seizing the opportunities it offers are establishing a lead over the rest. However the effort required implementing ecommerce successfully has to be sustained. It requires 
support form the highest level, identification of the questions that managers should ask them, and a willingness to rethink organisational processes. In a world which is increasingly competitive and where organisations are required to undertake greater levels of risk in order to compete, those companies that fail to act now may find they have left it too late as ecommerce has become a dominant way of doing business in their sector. By contrast, companies that have vision, a strategy, and a long-term outlook will find that by embracing e-commerce now, they will reinforce their market position.

However, this will not occur if the issues are not properly understood. This paper has provided twenty key questions for which managers must know the answers in order to enter e-commerce with sufficient understanding to give the company a reasonable chance of success.

\section{REFERENCES}

[1] C.Benko, "Global practice leader for e-business", Business International Journal, Vol.1, p.25, 2000.

[2] C.Chan and Swatmann, "B2B E-commerce implementation," Conference paper. RMIT University, Melbourne, P.M.C, 1999.
[3] L.M.Applegate, C.W.Holsapple, R.Kalakota F.Radermacer, "Electronic commerce: Building blocks of new business opportunity," Journal of Organisational Computing and Electronic Commerce, Vol.6, no. 1, pp 1-10, 1996.

[4] P.Daniels, Information Technology The Management Challenge, page 44, 1998.

[5] N.Bond, "Internet World", May, 2000.

[6] P.Cragg.and M.King, "Small firm computing motivators and inhibitors", MIS Quarterly, vol. 17, no.1,pp 47-60, 1993.

[7] N.Shah, N.Hague, M.Sokalska, "Managing IT Within Organisations", M.Sc. Report, Business School, Loughborough University, 1999.

[8] M.Hill, Project Management Notes, MSc management, Business school, Loughborough university, 1999.

[9] J.Thong and C.S.Yap, "Engagement of external expertise in information systems implementation" Journal of Management Information Systems, vol. 11, no 2, pp.209-31, 1994.

[10] P.Senge, The Fifth Discipline: The Art and Practice of the Learning Organisation, 1994.

[11] KPMG Board, "Questions for Executives and Board Members," KPMG Report, 1999. 